\title{
CORRECTIONS
}

\section{How do we know whether medical apps work?}

In this Observations article by Margaret McCartney (BMJ 2013;346:f1811, doi:10.1136/bmj.f1811) we should have stated that "an app from Skin Analytics ... offers to track changes in skin moles to 'raise early warning signs' by comparison with previous images of the same mole" [not "by comparison with an online database"].

Cite this as: BMJ 2013;346:f1974

๑ BMJ Publishing Group Ltd 2013 